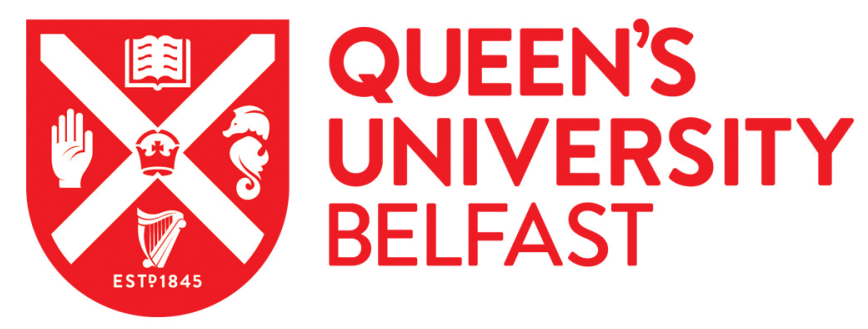

\title{
Comparisons between different polychemotherapy regimens for early breast cancer: meta-analyses of long-term outcome among 100,000 women in 123 randomised trials
}

Peto, R., Davies, C., Godwin, J., Gray, R., Pan, H. C., Clarke, M., Cutter, D., Darby, S., McGale, P., Taylor, C., Wang, Y. C., Bergh, J., Di Leo, A., Albain, K., Swain, S., Piccart, M., \& Pritchard, K. (2012). Comparisons between different polychemotherapy regimens for early breast cancer: meta-analyses of long-term outcome among 100,000 women in 123 randomised trials. The Lancet, 379(9814), 432-444.

https://doi.org/10.1016/S0140-6736(11)61625-5

Published in:

The Lancet

Document Version:

Publisher's PDF, also known as Version of record

Queen's University Belfast - Research Portal:

Link to publication record in Queen's University Belfast Research Portal

\section{Publisher rights}

Copyright (C) 2012 The Authors

This is an open access article published under a Creative Commons Attribution-NonCommercial-NoDerivs License

(https://creativecommons.org/licenses/by-nc-nd/4.0/), which permits distribution and reproduction for non-commercial purposes, provided the author and source are cited

\section{General rights}

Copyright for the publications made accessible via the Queen's University Belfast Research Portal is retained by the author(s) and / or other copyright owners and it is a condition of accessing these publications that users recognise and abide by the legal requirements associated with these rights.

\section{Take down policy}

The Research Portal is Queen's institutional repository that provides access to Queen's research output. Every effort has been made to ensure that content in the Research Portal does not infringe any person's rights, or applicable UK laws. If you discover content in the Research Portal that you believe breaches copyright or violates any law, please contact openaccess@qub.ac.uk. 


\section{Q ${ }^{+}$Comparisons between different polychemotherapy regimens for early breast cancer: meta-analyses of long-term outcome among 100000 women in 123 randomised trials}

Early Breast Cancer Trialists' Collaborative Group (EBCTCG)

\section{Summary}

Lancet 2012; 379: 432-44 Published Online December 6, 2011 DOI:10.1016/S01406736(11)61625-5

See Comment page 390

Correspondence to:

Early Breast Cancer Trialists' Collaborative Group (EBCTCG) Secretariat, Clinical Trial Service Unit (CTSU), Richard Doll

Building, Old Road Campus, Oxford OX3 7LF, UK

bc.overview@CTSU.ox.ac.uk

Background Moderate differences in efficacy between adjuvant chemotherapy regimens for breast cancer are plausible, and could affect treatment choices. We sought any such differences.

Methods We undertook individual-patient-data meta-analyses of the randomised trials comparing: any taxane-plusanthracycline-based regimen versus the same, or more, non-taxane chemotherapy $(n=44000)$; one anthracyclinebased regimen versus another $(n=7000)$ or versus cyclophosphamide, methotrexate, and fluorouracil (CMF; $n=18000)$; and polychemotherapy versus no chemotherapy $(n=32000)$. The scheduled dosages of these three drugs and of the anthracyclines doxorubicin (A) and epirubicin (E) were used to define standard CMF, standard 4AC, and CAF and CEF. Log-rank breast cancer mortality rate ratios (RRs) are reported.

Findings In trials adding four separate cycles of a taxane to a fixed anthracycline-based control regimen, extending treatment duration, breast cancer mortality was reduced (RR 0.86, SE 0.04, two-sided significance [2p]=0.0005). In trials with four such extra cycles of a taxane counterbalanced in controls by extra cycles of other cytotoxic drugs, roughly doubling non-taxane dosage, there was no significant difference (RR 0.94, SE 0.06, $2 \mathrm{p}=0$-33). Trials with CMF-treated controls showed that standard 4AC and standard CMF were equivalent (RR 0.98, SE 0.05, 2p=0.67), but that anthracycline-based regimens with substantially higher cumulative dosage than standard 4AC (eg, CAF or CEF) were superior to standard CMF (RR 0.78, SE $0.06,2 \mathrm{p}=0.0004$ ). Trials versus no chemotherapy also suggested greater mortality reductions with CAF (RR $0 \cdot 64$, SE $0 \cdot 09,2 p<0 \cdot 0001)$ than with standard 4AC (RR $0 \cdot 78, S E 0 \cdot 09,2 p=0 \cdot 01)$ or standard CMF (RR 0.76, SE 0.05, 2p<0.0001). In all meta-analyses involving taxane-based or anthracycline-based regimens, proportional risk reductions were little affected by age, nodal status, tumour diameter or differentiation (moderate or poor; few were well differentiated), oestrogen receptor status, or tamoxifen use. Hence, largely independently of age (up to at least 70 years) or the tumour characteristics currently available to us for the patients selected to be in these trials, some taxane-plus-anthracycline-based or higher-cumulative-dosage anthracycline-based regimens (not requiring stem cells) reduced breast cancer mortality by, on average, about one-third. 10-year overall mortality differences paralleled breast cancer mortality differences, despite taxane, anthracycline, and other toxicities.

Interpretation 10-year gains from a one-third breast cancer mortality reduction depend on absolute risks without chemotherapy (which, for oestrogen-receptor-positive disease, are the risks remaining with appropriate endocrine therapy). Low absolute risk implies low absolute benefit, but information was lacking about tumour gene expression markers or quantitative immunohistochemistry that might help to predict risk, chemosensitivity, or both.

Funding Cancer Research UK; British Heart Foundation; UK Medical Research Council.

Introduction

The Early Breast Cancer Trialists' Collaborative Group (EBCTCG) was established in 1985 to coordinate individual-patient-level meta-analyses of all randomised trials of adjuvant treatments..$^{1-4} \mathrm{~A}$ previous report ${ }^{1}$ on the trials that had begun by 1995 reviewed polychemotherapy versus no adjuvant chemotherapy and anthracyclinebased chemotherapy (with doxorubicin or epirubicin) versus CMF (cyclophosphamide, methotrexate, fluorouracil), but did not take dosage into account and did not review taxanes.

The present report reviews the preliminary taxane trial results and updates the other chemotherapy trial results, assessing the relevance of scheduled drug dosage and investigating whether any of the available patient or tumour characteristics (eg, age, nodal status, tumour differentiation, oestrogen receptor [ER] status, use of tamoxifen) affect the proportional reductions with modern chemotherapy in breast cancer recurrence and death.

\section{Methods}

Trials

Methods of trial identification, data checking, analysis, and involvement of trialists in the interpretation of results are as in previous EBCTCG reports. ${ }^{1-4}$ Information about each individual patient was sought during 2005-10 from all randomised trials begun during 1973-2003 of: (1) taxane-based versus non-taxane-based regimens (data for 33 trials, begun in 1994-2003); (2) any anthracyclinebased regimen versus standard or near-standard CMF 
(see table for the terminology used for these and selected other regimens; 20 trials, begun in 1978-97); (3) higher versus lower anthracycline dosage (six trials, begun in 1985-94); and (4) polychemotherapy versus no adjuvant chemotherapy (64 trials, begun in 1973-96, including 22 of various anthracycline-based regimens and 12 of standard or near-standard CMF).

Trials of intensive chemotherapy with stem-cell rescue or of variation only in dose-density are not included. Datasets from taxane trials had to await trial publication, so they arrived from 2005 to 2010; although 33 are included $(n=45000)$, three are not $(n=7000$; started by 2003 and unreported before mid-2010; see forest plot in webappendix p 23). Otherwise, all main analyses include $99 \%$ or more of all relevant patients in closed trials.

\section{Statistical analysis}

For each main chemotherapy comparison, forest plots (webappendix pp 21-62) describe the separate trials and their results, graphs illustrate absolute risks in various circumstances, and detailed subgroup analyses explore whether proportional risk reductions depend on patient or tumour characteristics. All text figures plus many more detailed analyses, and trial references, are in the webappendix (which needs magnified viewing).

Recurrence, ER, and nodal status are defined as before. Statistical analyses are stratified as before ${ }^{4}$ by trial, age, ER status, and, except in neoadjuvant trials, nodal status. If a log-rank statistic (o-e) has variance v, then, defining $z=(\mathrm{o}-\mathrm{e}) / \sqrt{ } \mathrm{v}$ and $b=(\mathrm{o}-\mathrm{e}) / \mathrm{v}$, the event rate ratio (RR, newer treatment $v$ s control) is estimated as $\exp (b)$ with standard error $\mathrm{SE}=(\mathrm{RR}-1) / z$. Either $\mathrm{RR}$ and its $\mathrm{SE}$ are cited, or confidence limits for RR are derived from those for $b$ (by normal approximations). $2 \mathrm{p}$ indicates two-sided significance, and $\mathrm{n}$ the number of patients to the nearest 500 or 1000 (with, for balance, control groups that were compared with more than one active group doublecounted or triple-counted).

Breast cancer mortality rate in each year is the overall mortality rate among all women minus that among women without recurrence. Breast cancer mortality RRs are estimated from the corresponding log-rank analyses of mortality with recurrence (obtained by subtracting log-rank analyses of mortality without recurrence [ie, censored at recurrence] from those of overall mortality; webappendix p 1). For indirect comparisons between different regimens, effects on early recurrence rates (years $0-4$ ) might be more sensitive than effects on other outcomes, because they are substantial and not materially affected by differences in follow-up duration (or chance effects on recurrence rates in later years when proportional reductions might be less extreme than in years $0-4)$, so the webappendix reports effects on early recurrence, any recurrence, and mortality.

For at least some major subgroup analyses to be statistically reliable, the overall $\chi^{2}{ }_{1}$ for the RR (treatment vs control) in all subgroups together should generally be large (eg, at least 25 , but preferably 50 , or even 100 ). For, if there is little real heterogeneity between the RRs, this overall $\chi_{1}^{2}$ (plus the small $\chi^{2}$ for heterogeneity between treatment RRs in different subgroups) gets partitioned between the subgroups in approximate proportion to numbers of events, to yield $\chi^{2}{ }_{1}$ in each. If $\chi^{2}{ }_{1}$ in a major subgroup should be only about 10 or less after such a split, chance could well make it non-significant or null. ${ }^{6}$ For, a subgroup-specific treatment effect that, given the overall findings, should be about $3 \mathrm{SE}$ (yielding $\chi_{1}^{2}=9$, $2 \mathrm{p}=0.003$ ) could easily by chance be less than 2SE (and hence not significant). Statistical analyses utilised programs written by the EBCTCG in FORTRAN.

\section{Role of the funding sources}

The funders had no role in study design, conduct, or reporting. The Secretariat had full access to all data. The decision to publish was by the writing committee, after circulation to all collaborators.

\section{Results}

\section{Taxane-based regimens versus active controls}

For each trial of taxane-based versus non-taxane-based chemotherapy, forest plots (webappendix pp 21-26) give results for early recurrence (years $0-4$ ), any recurrence, breast cancer mortality (mortality with recurrence, by log-rank subtraction), mortality without recurrence (first year only, all years), and overall mortality. Each forest plot gives one line per trial: year started, study name, regimens compared, results, and log-rank analyses.

Treatment comparisons varied greatly, which complicates meta-analyses. All but two trials (excluded from the meta-analyses) compared a taxane-plus-anthracyclinebased regimen versus an anthracycline-based control regimen with the same or more of each non-taxane component. Averaging the results for all such trials to test for some taxane effect (by summing the trial-specific logrank statistics; webappendix pp 7-8 and 21-26; $n=44000$ ), the RRs were 0.87 (SE 0.03) for distant recurrence, 0.86 (SE $0 \cdot 02, \chi^{2}=47 \cdot 7,2 \mathrm{p}<0 \cdot 00001$ ) for any recurrence, $0 \cdot 87$ (SE $0.03, \quad \chi_{1}^{2}=22 \cdot 0,2 \mathrm{p}<0 \cdot 00001$ ) for breast cancer mortality, $0 \cdot 99$ (SE $0 \cdot 08$, no net hazard) for other mortality, and 0.89 (SE $0 \cdot 03,2 \mathrm{p}<0 \cdot 00001)$ for overall mortality.

\begin{tabular}{|c|c|}
\hline & Scheduled number of cycles and cytotoxic treatment per cycle \\
\hline Standard CMF & 6 cycles of $\mathrm{C}_{100 \times 14} \mathrm{M} 40 \times 2 \mathrm{~F} 500 \times 2$, given 4-weekly; widely studied \\
\hline Near-standard $\mathrm{CMF}^{5}$ & $6-12$ cycles with same doses as standard CMF and/or $C 600 \times 2$ replacing $C 100 \times 14$ \\
\hline Standard $4 \mathrm{AC}$ & 4 cycles of A60 C600, given iv 3-weekly; widely studied \\
\hline Standard 4EC & 4 cycles of E90 C600, given iv 3-weekly \\
\hline CAF & 6 cycles of $\mathrm{C} 100 \times 14 \mathrm{~A} 30 \times 2 \mathrm{~F} 500 \times 2$, given 4-weekly \\
\hline CEF & 6 cycles of $\mathrm{C} 75 \times 14 \mathrm{E} 60 \times 2 \mathrm{~F} 500 \times 2$, given 4-weekly \\
\hline \multicolumn{2}{|c|}{$\begin{array}{l}\text { Data are drug dose, } \mathrm{mg} / \mathrm{m}^{2} \times \text { frequency per cycle }(\times 14=\text { days } 1-14 \text { oral; } \times 2=\text { days } 1 \text { and } 8 \mathrm{iv}) \text {. Tabulated treatment } \\
\text { schedules do not include any supportive care or cytotoxic dose reduction for acute toxicity. } \mathrm{C}=\text { cyclophosphamide. } \\
\mathrm{M=methotrexate.} \mathrm{F}=\text { fluorouracil. } \mathrm{A}=\text { doxorubicin (Adriamycin). } \mathrm{E}=\text { epirubicin. iv=intravenous. }\end{array}$} \\
\hline
\end{tabular}




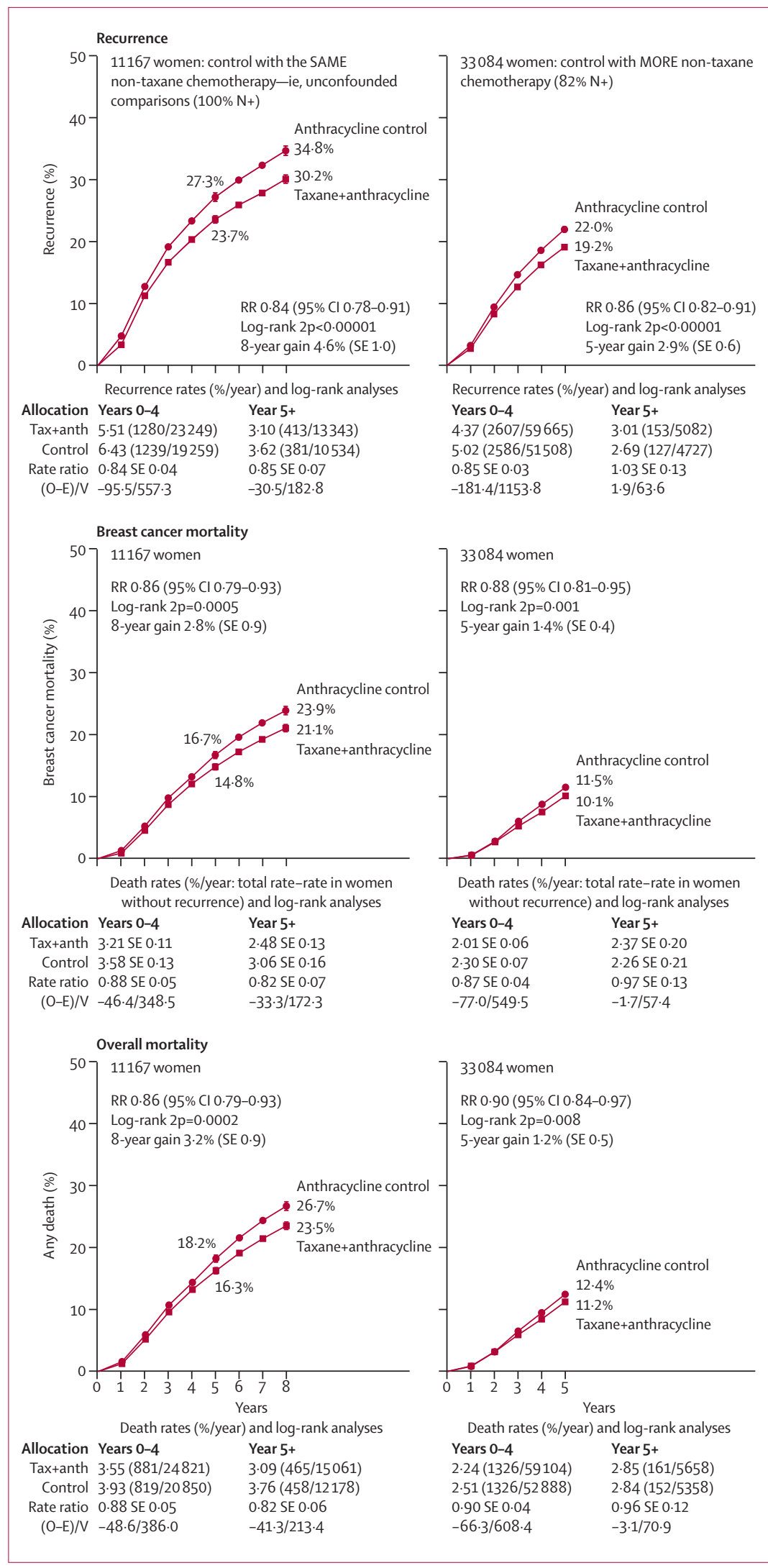

These varied treatment comparisons can be grouped by how the chemotherapy regimen in the control group compared with the non-taxane chemotherapy in the taxane group: the same (ie, unconfounded trials of the effects of adding four separate cycles just of a taxane to a constant background chemotherapy regimen, thereby prolonging treatment duration; $\mathrm{n}=11000$ ), double (ie, strongly confounded trials in which the effects of adding four separate cycles of a taxane to an anthracycline-based regimen were counterbalanced in controls by roughly doubling the number of cycles of non-taxane chemotherapy; $n=10000$ ), or intermediate $(n=23000)$. Only in some of the trials with an intermediate control regimen was the taxane given concurrently with any other cytotoxic agents.

In the unconfounded taxane trials, which all began in 1994-99, little follow-up beyond year 8 is yet available; figure 1 (left-hand side) gives absolute effects on 8 -year recurrence, breast mortality, and overall mortality in these trials. Effects were moderate for recurrence, and slightly smaller (but still highly significant) for breast cancer mortality and overall mortality. 8-year breast cancer mortality was $21.1 \%$ for the taxane groups versus $23.9 \%$ for the control groups (absolute gain 2.8\%, SE 0.9; RR $0 \cdot 86$, SE $0 \cdot 04,2 p=0 \cdot 0005$ ); for overall mortality the absolute gain was similar. By contrast, in the trials of adding four cycles of a taxane versus roughly doubling the non-taxane chemotherapy, there was little net difference in recurrence, breast cancer mortality (foot of figure $2 \mathrm{~A} ; \mathrm{n}=10000$; $\mathrm{RR} 0 \cdot 94$, SE $0 \cdot 06,2 \mathrm{p}=0 \cdot 16$ ), or overall mortality (webappendix pp 7-8 and 21-26); again, however, comparisons varied, and follow-up was short.

Figure 1 (right-hand side) describes these and all other trials in which the effects of the taxane were counterbalanced by giving the controls more non-taxane chemotherapy $(\mathrm{n}=33000$ with data on numbers dead in each treatment group, only 30000 of whom had data on the times to any deaths; webappendix p 23). In these confounded taxane trials, little follow-up beyond 5 years is yet available, but on average their 5 -year findings again show small but significant reductions in recurrence, breast cancer mortality, and overall mortality. Chemotherapy regimens varied greatly, so real treatment effects in different trials could well differ, even though chance makes it difficult to assess this reliably, particularly with short follow-up and some trials not yet available. Only one trial (GEICAM99067) involved weekly paclitaxel.

Figure 2 shows selected subgroup analyses for breast cancer mortality in all 44000 women. Its first three sections group the treatment comparisons in various ways, without

Figure 1: Time to recurrence, breast cancer mortality, and overall mortality for taxane-plus-anthracycline-based regimens (Tax+anth) versus control with (left) the same or (right) more non-taxane chemotherapy Trials versus the same non-taxane chemotherapy (usually 4AC) just added four extra taxane-only cycles. RR (and its $95 \% \mathrm{Cl}$ )=event rate ratio, from summed log-rank statistics for all time periods combined. Gain (and its $\mathrm{SE}$ )=absolute difference between ends of graphs. Event rates, \%/year, are followed by (first events/woman-years). Error bars show $\pm 1 \mathrm{SE}$. 
finding clear evidence of differences in the average treatment effect. Its first section groups the taxane comparisons as unconfounded, intermediate, or strongly confounded, as above (for the trial-specific details corresponding to these groupings see webappendix pp 21-26) and the next two sections group the treatment

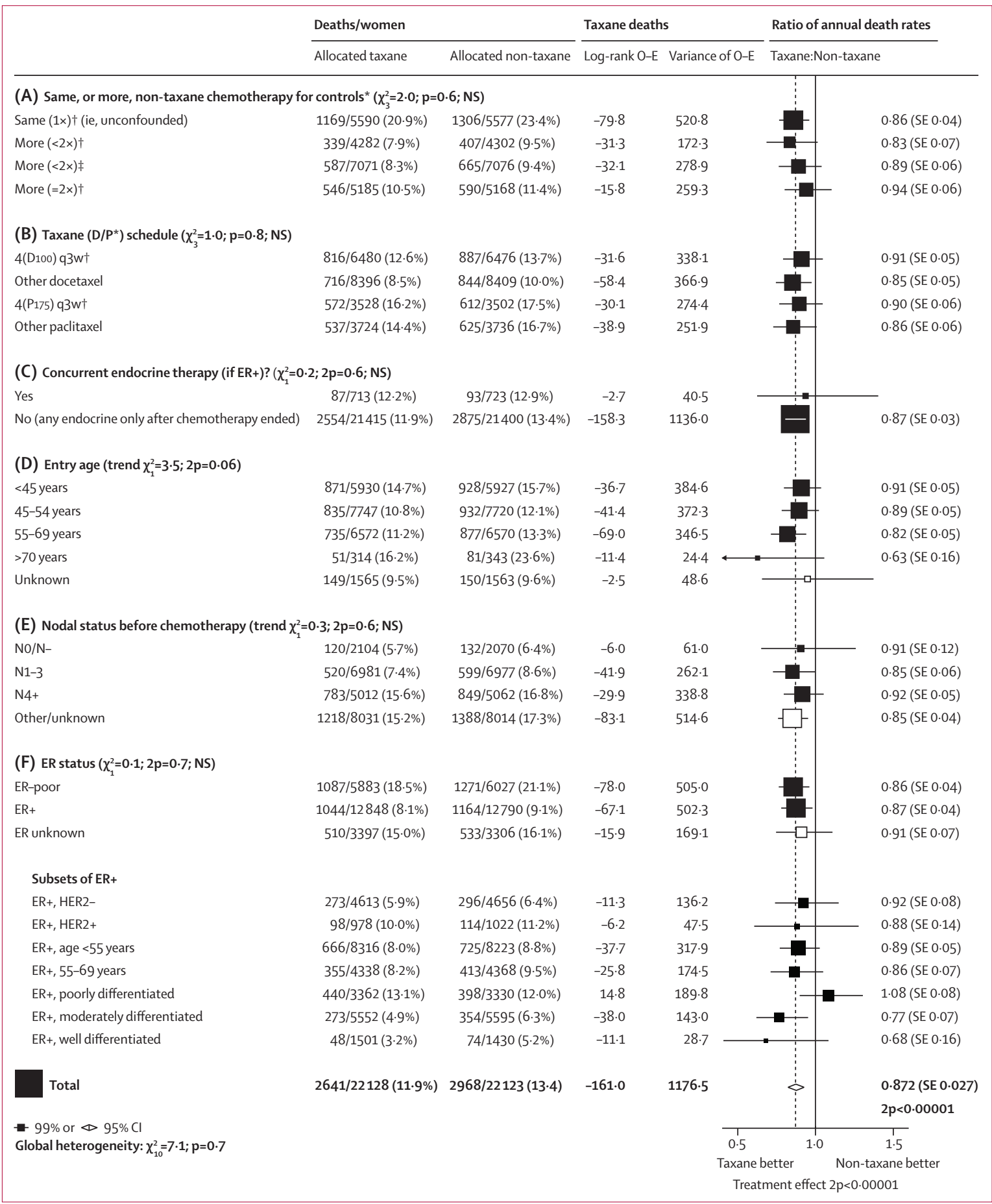

Figure 2: Subgroup analyses of breast cancer mortality (mortality with recurrence, by log-rank subtraction) for taxane-plus-anthracycline-based regimens versus the same, or more (less than doubled or roughly doubled), non-taxane cytotoxic chemotherapy $\mathrm{D}=$ docetaxel. $\mathrm{P}=$ paclitaxel. $4(\mathrm{D} 100) \mathrm{q} 3 \mathrm{w}=$ four doses of docetaxel $100 \mathrm{mg} / \mathrm{m}^{2}$ at intervals of 3 weeks. 4(P175) $\mathrm{q} 3 \mathrm{w}=$ four doses of paclitaxel $175 \mathrm{mg} / \mathrm{m}^{2}$ at intervals of 3 weeks. ER=oestrogen receptor. NS=not significant. *First four subgroups are as in the forest plots (webappendix pp 21-26) that give details of each trial's cytotoxic regimens. †Taxane courses do not overlap other chemotherapy courses. $¥$ Taxane given concurrently with anthracycline. 


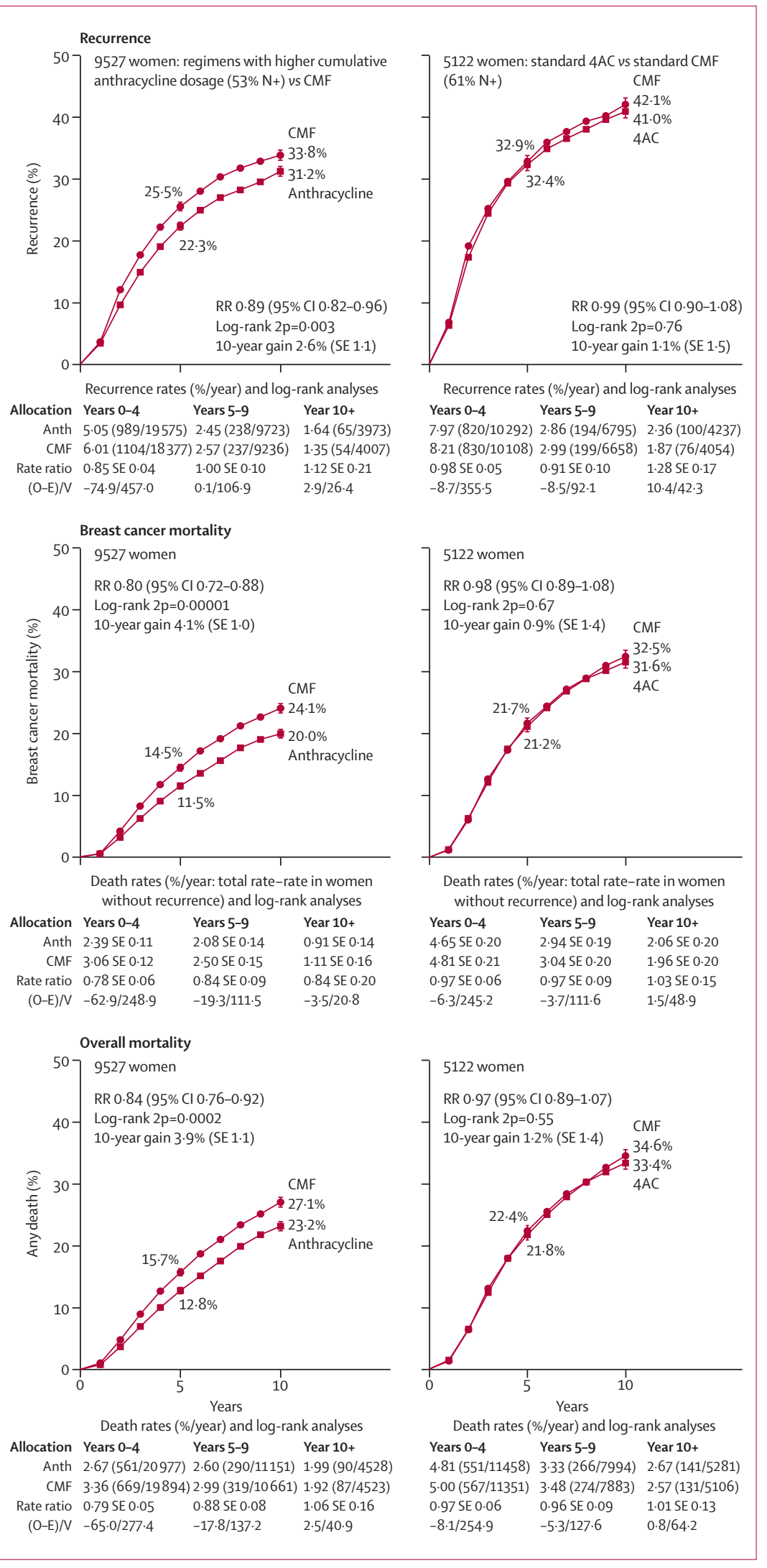

comparisons in other ways. Later sections, again without clear evidence of heterogeneity of treatment effect, subdivide by age (finding significant benefit even at ages 55-69 years; few were older, but their results suggest favourable effects of taxanes even in old age), nodal status before chemotherapy (4000 had node-negative disease), and ER status. Results are also given for subsets of ERpositive disease by HER2 status (generally by immunohistochemistry, classified where possible by standard criteria for definite positivity ${ }^{8}$ ), age, and differentiation (with a trend towards greater taxane benefit in well differentiated [RR $0 \cdot 68$, SE $0 \cdot 16,2 \mathrm{p}=0 \cdot 04, \mathrm{n}=3000$ ] or moderately differentiated [RR $0 \cdot 77$, SE $0 \cdot 07,2 \mathrm{p}=0 \cdot 001$, $\mathrm{n}=11000]$ ER-positive tumours than in poorly differentiated ER-positive tumours). Most of the women with ER-positive disease had endocrine therapy after their chemotherapy.

More detailed subgroup analyses of recurrence and breast cancer mortality (webappendix pp 7-8) found no consistent heterogeneity of the proportional risk reductions by age, nodal status, ER status, progesterone receptor status, tumour differentiation (although only 4000 were well differentiated; webappendix $\mathrm{p} 8$ ), tumour diameter, or combinations of these. Proportional risk reductions appeared similar in years $0-1,2-4$, and (provisionally) 5+ after entry, so the indirect treatment comparisons in figure 2 should not have been materially affected by differences between taxane trials in followup duration. If there is real heterogeneity between effects in different subgroups, this should be clearer for recurrence (overall $\chi_{1}^{2}=48$ ) than for breast cancer mortality (overall $\chi_{1}^{2}=22$ ), but neither $\chi^{2}$ value is big enough for subgroup analyses to be wholly reliable.

\section{Anthracycline-based regimens versus active controls}

For trials of an anthracycline-based regimen versus CMF, forest plots for each of several different outcomes (webappendix pp 27-32) give one descriptive line per trial: name, regimens compared, and results. The control regimen was generally standard CMF (otherwise it was near-standard CMF; to challenge anthracycline-based regimens rigorously, however, these analyses exclude CMF regimens with the dose per cycle of any drug less than that in near-standard CMF; see table). Again, most of the women with ER-positive disease would have been given endocrine therapy after their chemotherapy.

Figure 3 (left-hand side; $n=9500$ ) shows results from the trials with anthracycline dose per cycle at least $60 \mathrm{mg} / \mathrm{m}^{2}$ doxorubicin or $90 \mathrm{mg} / \mathrm{m}^{2}$ epirubicin and with

Figure 3: Time to recurrence, breast cancer mortality, and overall mortality for selected anthracycline-based regimens versus standard or near-standard CMF Left: regimens with cumulative dosage greater than $240 \mathrm{mg} / \mathrm{m}^{2}$ doxorubicin or $360 \mathrm{mg} / \mathrm{m}^{2}$ epirubicin (eg, CAF or CEF). Right: standard 4AC (cumulative dosage $240 \mathrm{mg} / \mathrm{m}^{2}$ doxorubicin). All graphs exclude regimens with less than $60 \mathrm{mg} / \mathrm{m}^{2}$ doxorubicin or $90 \mathrm{mg} / \mathrm{m}^{2}$ epirubicin per cycle. $\mathrm{RR}$ (and its $95 \% \mathrm{Cl}$ )=event rate ratio, from summed log-rank statistics for all time periods combined. Gain (and its $\mathrm{SE}$ )=absolute difference between ends of graphs. Anth=anthracycline. Event rates, \%/year, are followed by (first events/woman-years). Error bars show $\pm 1 \mathrm{SE}$. 
cumulative anthracycline dosage more than $240 \mathrm{mg} / \mathrm{m}^{2}$ doxorubicin or $360 \mathrm{mg} / \mathrm{m}^{2}$ epirubicin (eg, CAF or CEF). The findings for recurrence, breast cancer mortality, and overall mortality show a definite improvement over CMF. Averaging the results for all these trials, the RRs were 0.89 for recurrence (SE $0 \cdot 04,2 p=0.003$; this included what might have been mainly a chance excess incidence of contralateral disease), 0.80 for breast cancer mortality (SE $0 \cdot 05,2 \mathrm{p}=0 \cdot 00001$ ), and 0.84 for overall mortality (SE $0 \cdot 04, \chi_{1}^{2}=9 \cdot 9,2 \mathrm{p}=0 \cdot 0002$ ). By contrast, standard 4AC and standard CMF appeared equivalent (right-hand side of figure $3 ; n=5000$ ).

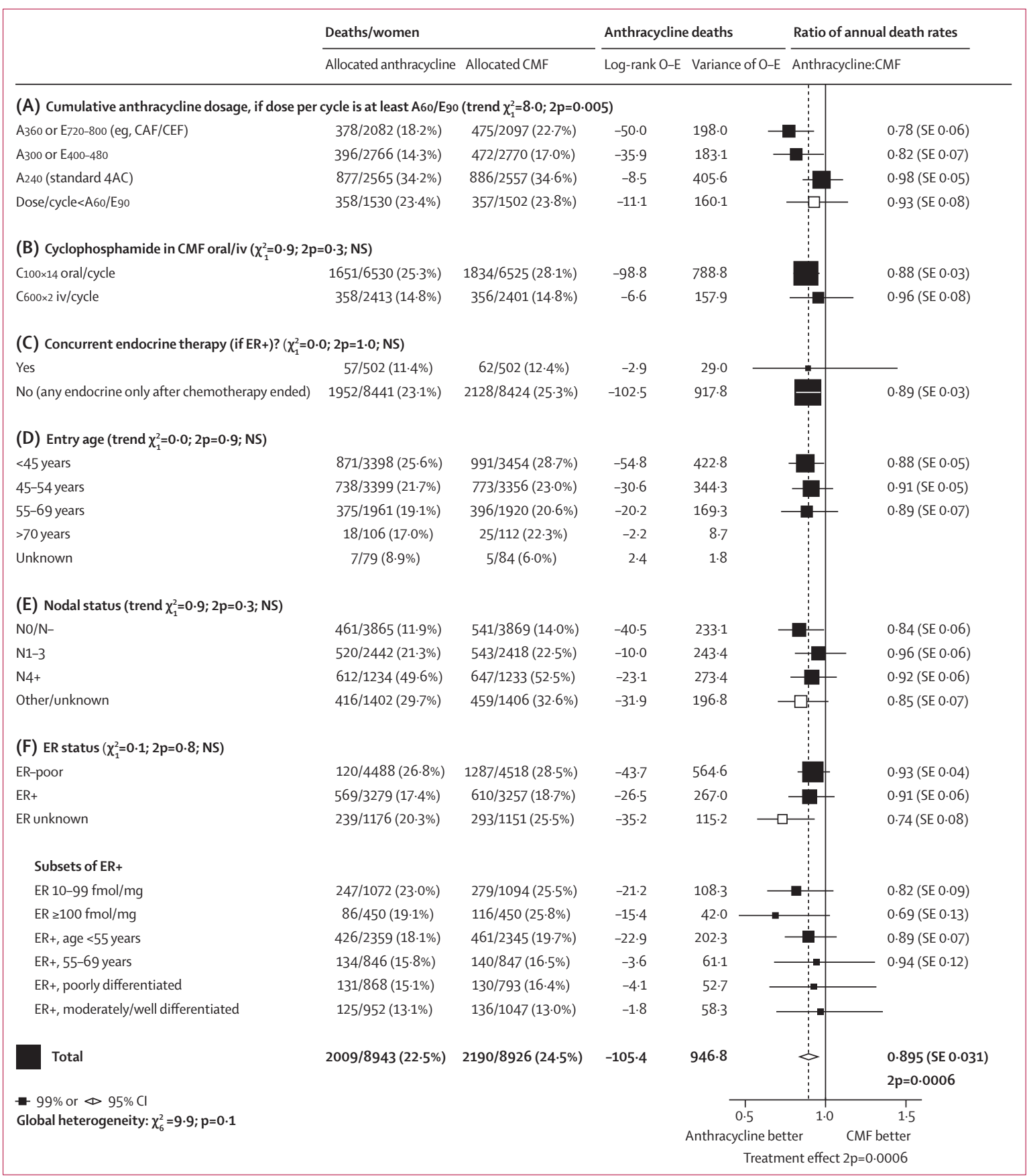

Figure 4: Subgroup analyses of breast cancer mortality (mortality with recurrence, by log-rank subtraction) for any anthracycline-based regimen versus standard CMF (or near-standard CMF)

$\mathrm{A}=$ doxorubicin (Adriamycin). $\mathrm{E}=$ epirubicin. Dose/cycle (and cumulative dosage) is given after the drug name in $\mathrm{mg} / \mathrm{m}^{2} ; \mathrm{A} 60 / \mathrm{E} 90 \mathrm{means} 60 \mathrm{mg} / \mathrm{m}^{2}$ of doxorubicin or $90 \mathrm{mg} / \mathrm{m}^{2}$ of epirubicin. iv=intravenous. NS=not significant. ER=oestrogen receptor. $\mathrm{IHC}=$ immunohistochemistry. *First four subgroups are as in the forest plots (webappendix pp 27-32) that give details of each trial's cytotoxic regimens. 
In these trials there was a significant trend towards greater efficacy with higher cumulative anthracycline dosage $\left(\chi^{2}=8 \cdot 0,2 p=0 \cdot 005\right.$; figure $\left.4 \mathrm{~A}\right)$. This trend was not necessarily due just to the extra anthracycline, however, because higher dosage was often accompanied by other additional chemotherapy (webappendix $p$ 29). The regimens with the highest cumulative anthracycline dosage include CAF and CEF (which, like standard CMF, have 14 days per cycle of oral cyclophosphamide), and were, on average, significantly better than standard CMF at reducing breast cancer mortality (RR 0.78 , SE 0.06 , $2 \mathrm{p}=0 \cdot 0004$; figure $4 \mathrm{~A})$.

The foregoing comparisons between the effects of different anthracycline-based regimens in different trials are indirect. Few trials have compared directly one anthracycline-based regimen versus another (webappendix pp 45-50), and their results are not yet mature. Those in which all drugs varied together showed significantly greater efficacy with higher than lower dosage. Trials in which only the anthracycline dose per cycle varied showed, in aggregate, only non-significantly greater efficacy; one compared a standard versus lower anthracycline dose per cycle (GFEA05:' epirubicin 100 vs $50 \mathrm{mg} / \mathrm{m}^{2}$ per cycle, $n=500$ ), finding the standard dose significantly more effective, and one compared a standard dose versus two higher anthracycline doses per cycle (CALGB9344: doxorubicin 90 vs 75 vs $60 \mathrm{mg} / \mathrm{m}^{2}$ per cycle, $\mathrm{n}=3000$ ), finding no significant difference in efficacy between the highest and lowest doses. Although the latter comparison suggests little gain from the higher dose per cycle, the CIs associated with it do not preclude moderate further gain.

The anthracycline-based regimens varied greatly, so their average effect underestimates the effects of the better ones, and is given mainly to exclude the hypothesis that none is better than standard CMF and to help to assess safety. Averaging the results for all these trials of any anthracyclinebased regimen versus CMF (webappendix pp 9-10 and 31-32; $n=18000$ ), the RRs were 0.88 (SE 0.03, $\chi^{2}{ }_{1}=14 \cdot 4$, $2 \mathrm{p}=0 \cdot 0002$ ) for distant recurrence, 0.93 (SE 0.03, $\chi^{2}{ }_{1}=6 \cdot 5$, $2 \mathrm{p}=0.01$ ) for any recurrence, $0.89\left(\mathrm{SE} 0.03, \chi^{2}{ }_{1}=12 \cdot 0\right.$, $2 \mathrm{p}=0.0006$ ) for breast cancer mortality, 1.02 (SE 0.09, no significant difference) for other mortality, and 0.91 (SE $0 \cdot 03, \chi_{1}^{2}=9 \cdot 9,2 \mathrm{p}=0 \cdot 002$ ) for overall mortality.

Figure 4 (and webappendix pp 9-10) split the overall results by patient characteristics, site of first recurrence, and time period. (HER2 status was unavailable.) These subgroup analyses did not show heterogeneity of the proportional risk reduction by age, nodal status, ER status, ER level, or tumour differentiation or diameter. Since, however, the overall $\chi^{2}{ }_{1}$ (for the average treatment effect in all patients in all trials) was only $12 \cdot 0$, which is too small for subgroup analyses to be reliable, non-significant results in any particular subgroup are uninformative.

Conversely, significant results in particular subgroups might well reflect chance exaggerations (eg, the anthracycline-based regimens appeared better than CMF only if ER status was untested; figure 4). Likewise, chance in small subgroups could well explain why anthracyclines appeared particularly effective for disease with ER greater than $100 \mathrm{fmol} / \mathrm{mg}$ cytosol protein (RR 0.69 , SE $0 \cdot 13$, $2 \mathrm{p}=0 \cdot 02$ ). For each subgroup, the best evidence as to whether particular anthracycline-based regimens are better than standard CMF is from the results in all women, ER-tested or not. ${ }^{6}$

\section{Chemotherapy versus no-chemotherapy controls}

For each trial of an anthracycline-based regimen or of standard or near-standard CMF versus no adjuvant chemotherapy, forest plots for several outcomes (webappendix pp 33-44) give one descriptive line per trial. Although these 25-year-old trials of chemotherapy versus not (median start date 1986, IQR 1980-90) provide some further evidence about the comparative efficacy of different regimens, none studied taxanes, half gave no endocrine therapy, supportive care during treatment was sometimes suboptimal, and toxicity concerns probably limited dosage (since chemotherapy was of uncertain value, particularly for older women, when these trials were done). Finally, the populations in different trials differed: in the anthracycline trials only $18 \%$ had node-negative disease $(66 \%$ in the CMF trials) and only $11 \%$ of first recurrences were locoregional (33\% in the CMF trials; details in webappendix pp 11 and 13). Nevertheless, these old trials versus no chemotherapy still have some relevance to future patients.

Figure 5 shows 10-year outcomes for any anthracyclinebased regimen versus no chemotherapy (left-hand side; one trial studied CAF and a few studied standard 4AC, but most studied regimens with a substantially lower anthracycline dose per cycle) and for CMF versus no chemotherapy (right-hand side; standard CMF or nearstandard CMF). In both cases the main recurrence reductions were during years $0-4$, but for breast cancer mortality there were gains throughout the first decade. During years $0-4$, the absolute effects on breast cancer mortality and on overall mortality were similar, suggesting little net adverse effect on other mortality, but later nonbreast-cancer mortality was somewhat greater with chemotherapy, although 10-year overall mortality was still reduced (webappendix pp 42-44). Further follow-up is needed of longer-term effects on breast cancer mortality, on other mortality, and on overall mortality.

For any anthracycline-based regimen versus no chemotherapy (figure 5; webappendix pp 11 and 37; $\mathrm{n}=8500$ ), RRs were 0.69 (SE 0.04) for distant recurrence, $0 \cdot 73\left(\mathrm{SE} 0 \cdot 03, \chi^{2}{ }_{1}=70 \cdot 3\right)$ for any recurrence, $0 \cdot 79$ (SE 0 04, $\chi_{1}^{2}=33.7$ ) for breast cancer mortality, 1.20 (SE 0.10 $2 \mathrm{p}=0.05$ for increase) for other mortality, and 0.84 (SE $0 \cdot 03,2 \mathrm{p}<0 \cdot 00001$ ) for overall mortality. Several different regimens were tested. For CMF versus no chemotherapy (figure 5; webappendix pp 13 and 43; $\mathrm{n}=5000$ ), RRs were 0.66 (SE 0.05) for distant recurrence, $0 \cdot 70\left(\mathrm{SE} 0 \cdot 04, \chi^{2}{ }_{1}=55 \cdot 6\right)$ for any recurrence, $0 \cdot 76$ (SE 0.05, $\left.\chi_{1}^{2}=24 \cdot 8, \quad 2 \mathrm{p}<0 \cdot 00001\right)$ for breast cancer mortality, 1.24 (SE $0 \cdot 12,2 \mathrm{p}=0.05$ for increase) for other mortality, 
and $0 \cdot 84(\mathrm{SE} 0 \cdot 05,2 \mathrm{p}=0 \cdot 0004)$ for overall mortality. Most of these trials studied standard CMF (and the remainder studied near-standard CMF; see table).

Treatment effects are larger for chemotherapy versus no chemotherapy than for one type of chemotherapy versus another, and because the $\chi^{2}$ values for the overall effects are fairly large, the findings in some major subgroups could be informative. In the webappendix (pp 11-14), the findings for early recurrence (years 0-4), any recurrence, and breast cancer mortality are split by treatment schedule, detailed patient characteristics, site of first recurrence, and time period. For anthracyclinebased regimens, there was no good evidence of any heterogeneity of the proportional risk reductions with age, nodal status, ER status, tumour differentiation, tumour diameter, or combinations of these.

Figure 6 gives some of these subgroup analyses for anthracycline-based regimens. By contrast with figure 4, few trials had $60 \mathrm{mg} / \mathrm{m}^{2}$ doxorubicin per cycle or $90 \mathrm{mg} / \mathrm{m}^{2}$ epirubicin per cycle. Most that did studied CAF (SWOG8814, ${ }^{11} \mathrm{n}=1500$ [allocated in 3:1 ratio]) or standard 4AC $(n=1500)$. Although the difference between the apparent effects of these two regimens was not significant, CAF (RR 0.64, SE 0.09) appeared somewhat more effective than standard 4AC or 4EC (RR 0.78, SE 0.09). The other regimens, all with lower anthracycline dose per cycle (but, in some, additional other drugs), appeared, on average, almost as effective (RR 0.82, SE 0.05) as standard 4AC. Taking all these trials of anthracycline-based regimens together, the average effect approximated that of standard 4AC (or of standard CMF).

The proportional risk reductions appeared similar in trials of chemotherapy versus no adjuvant therapy and in trials of chemotherapy and tamoxifen (generally started concurrently) versus tamoxifen alone (figure 6C), suggesting that chemotherapy effects and tamoxifen effects are largely independent. Supporting this finding, in ER-positive disease the proportional risk reductions produced by tamoxifen appeared similar in trials of tamoxifen versus no adjuvant therapy and in trials of chemotherapy plus tamoxifen (started concurrently) versus chemotherapy alone. ${ }^{4}$ In addition to these indirect comparisons, there are four directly randomised comparisons of concurrent versus sequential chemoendocrine therapy, ${ }^{11-14}$ but some were not available to us.

In figure 6 (and webappendix pp 11-12), the proportional effects of anthracycline-based regimens on breast cancer outcomes did not depend much on age, nodal status, ER status, or, if ER-positive, on endocrine therapy, age, nodal status, tumour differentiation, or ER level

Figure 5: Time to recurrence, breast cancer mortality, and overall mortality for chemotherapy versus no adjuvant chemotherapy Left: four or more cycles of any anthracycline (Anth)-based regimen-eg, standard 4AC. Right: standard or near-standard CMF. RR (and its 95\% Cl)=event rate ratio, from summed log-rank statistics for all time periods combined. Gain (and its $\mathrm{SE}$ )=absolute difference between ends of graphs. $(T X=$ chemotherapy. Event rates, \%/year, are followed by (first events/woman-years). Error bars show $\pm 1 \mathrm{SE}$.

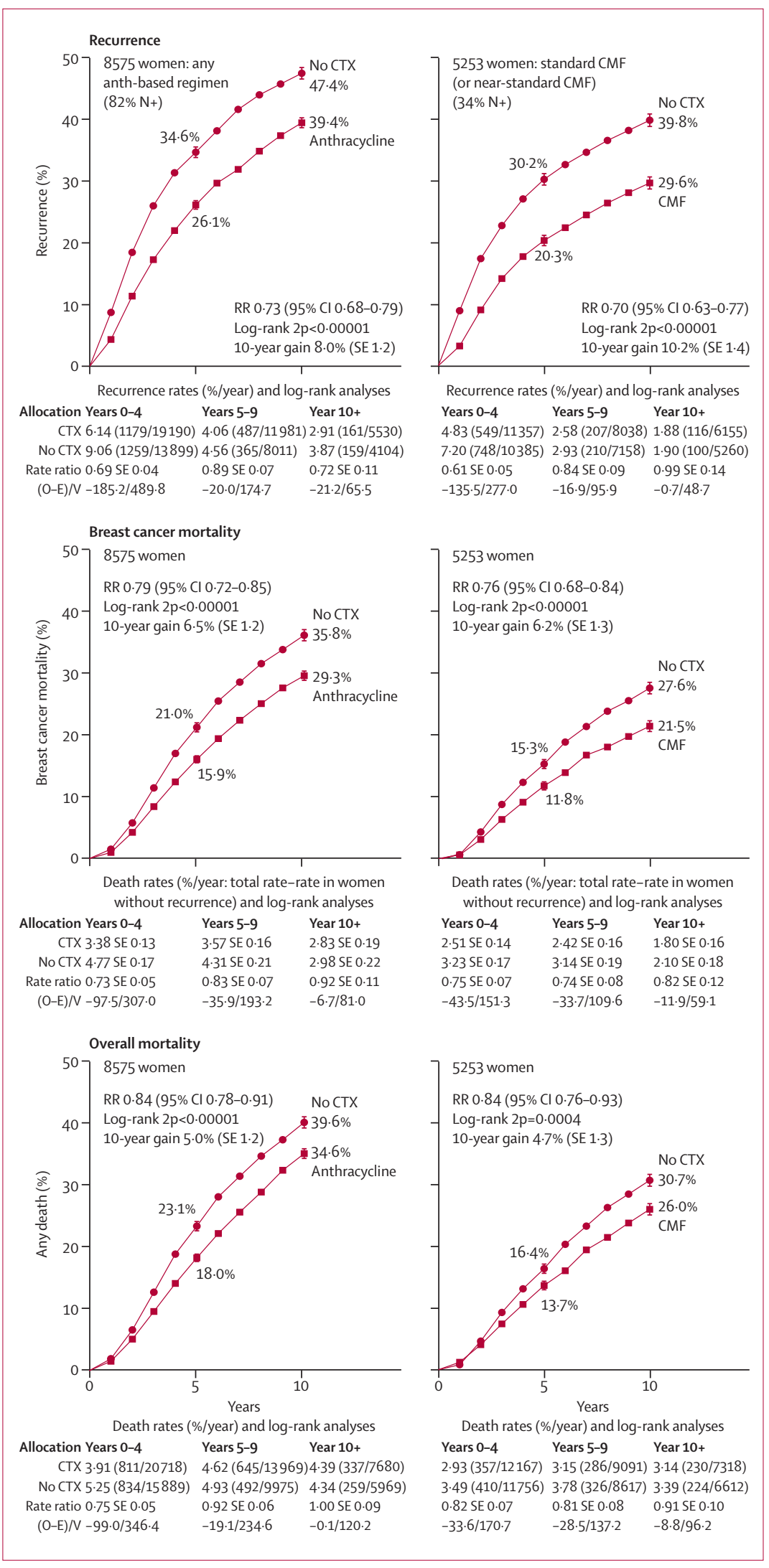


(10-99 or $>100 \mathrm{fmol} / \mathrm{mg})$. This finding suggests that the extreme RR in figure 4 for disease with ER greater than $100 \mathrm{fmol} / \mathrm{mg}$ could be partly a chance subgroup finding.
Combination of the breast cancer mortality results for disease with ER greater than $100 \mathrm{fmol} / \mathrm{mg}$ for any anthracycline-based regimen versus no chemotherapy and

\begin{tabular}{|c|c|c|c|c|c|c|}
\hline & \multicolumn{2}{|l|}{ Deaths/women } & \multicolumn{2}{|c|}{ Anthracycline deaths } & \multirow{2}{*}{\multicolumn{2}{|c|}{$\begin{array}{l}\text { Ratio of annual death rates } \\
\text { Anthracycline:Control }\end{array}$}} \\
\hline & Allocated anthracycline & Allocated control & Log-rank O-E & Variance of $\mathrm{O}-\mathrm{E}$ & & \\
\hline \multicolumn{7}{|c|}{ (A) Cumulative anthracycline dosage, if dose per cycle is at least $A 60 / E_{90}\left(\chi^{2}=1 \cdot 5 ; 2 p=0.2 ; N S\right)$} \\
\hline A360 (CAF) & $324 / 1177(27 \cdot 5 \%)$ & $456 / 1143(39 \cdot 9 \%)$ & $-35 \cdot 3$ & $80 \cdot 3$ & & 0.64 (SE 0.09) \\
\hline A300 (no trials) & .. & .. & & .. & & \\
\hline A240/E360 (standard 4AC/EC) & $212 / 747(28 \cdot 4 \%)$ & $265 / 792(33 \cdot 5 \%)$ & $-25 \cdot 6$ & $100 \cdot 5$ & & 0.78 (SE 0.09) \\
\hline Dose/cycle<A60/E90 & $880 / 2830(31 \cdot 1 \%)$ & $980 / 2798(35 \cdot 0 \%)$ & $-79 \cdot 0$ & $400 \cdot 5$ & & 0.82 (SE 0.05) \\
\hline \multicolumn{7}{|l|}{ (B) Anthracycline tested ${ }^{*}\left(\chi_{1}^{2}=1 \cdot 9 ; 2 p=0 \cdot 2 ; N S\right)$} \\
\hline Doxorubicin (A) & $973 / 2626(37 \cdot 1 \%)$ & $1185 / 2570(46 \cdot 1 \%)$ & $-106 \cdot 1$ & $370 \cdot 4$ & & 0.75 (SE 0.05) \\
\hline Epirubicin (E) & $293 / 1283(22 \cdot 8 \%)$ & $318 / 1283(24 \cdot 8 \%)$ & $-20 \cdot 5$ & $138 \cdot 4$ & & $0.86($ SE 0.08) \\
\hline A or E & $150 / 845(17 \cdot 8 \%)$ & $198 / 880(22 \cdot 5 \%)$ & $-13 \cdot 3$ & $72 \cdot 5$ & & $0.83($ SE 0.11) \\
\hline \multicolumn{7}{|c|}{ (C) Concurrent endocrine therapy (if $\mathrm{ER}+) ?\left(\chi_{1}^{2}=0 \cdot 3 ; 2 \mathrm{p}=0 \cdot 6 ; \mathrm{NS}\right)$} \\
\hline Yes & $607 / 2004(30 \cdot 3 \%)$ & 693/2014 (34.4\%) & $-54 \cdot 4$ & 288.0 & & $0.83($ SE 0.05) \\
\hline No (any endocrine only after chemotherapy ended) & $462 / 1431(32 \cdot 3 \%)$ & $514 / 1398(36 \cdot 8 \%)$ & $-48 \cdot 2$ & $203 \cdot 8$ & & 0.79 (SE 0.06) \\
\hline Random $\dagger$ & $347 / 1319(26 \cdot 3 \%)$ & $494 / 1321(37 \cdot 4 \%)$ & $-37 \cdot 2$ & $89 \cdot 4$ & & 0.66 (SE 0.09) \\
\hline \multicolumn{7}{|l|}{ (D) Entry age (trend $\chi_{1}^{2}=2 \cdot 0 ; 2 p=0 \cdot 2 ; \mathrm{NS}$ ) } \\
\hline$<45$ years & 135/402 (33.6\%) & $127 / 353(36.0 \%)$ & $-4 \cdot 9$ & $53 \cdot 0$ & & 0.91 (SE 0.13) \\
\hline 45-54 years & $338 / 1115(30 \cdot 3 \%)$ & $419 / 1175(35 \cdot 7 \%)$ & $-34 \cdot 9$ & 139.8 & & 0.78 (SE 0.07) \\
\hline $55-69$ years & $899 / 2995(30 \cdot 0 \%)$ & $1071 / 2956(36 \cdot 2 \%)$ & $-88 \cdot 5$ & $377 \cdot 0$ & & 0.79 (SE 0.05) \\
\hline$>70$ years & $43 / 225(19 \cdot 1 \%)$ & $84 / 232(36 \cdot 2 \%)$ & $-11 \cdot 7$ & $11 \cdot 4$ & & 0.36 (SE 0.19) \\
\hline Unknown & $1 / 17(5 \cdot 9 \%)$ & $0 / 17(0 \cdot 0 \%)$ & 0.2 & 0.1 & & \\
\hline \multicolumn{7}{|l|}{ (E) Nodal status (trend $\chi_{1}^{2}=0 \cdot 0 ; 2 \mathrm{p}=0 \cdot 9 ; \mathrm{NS}$ ) } \\
\hline NO/N- & $122 / 789(15 \cdot 5 \%)$ & $137 / 761(18.0 \%)$ & $-12 \cdot 0$ & 56.9 & & 0.81 (SE 0.12) \\
\hline N1-3 & $513 / 2257(22 \cdot 7 \%)$ & $604 / 2217(27 \cdot 2 \%)$ & $-51 \cdot 3$ & $214 \cdot 1$ & & 0.79 (SE 0.06) \\
\hline $\mathrm{N} 4+$ & $575 / 1226(46 \cdot 9 \%)$ & $741 / 1295(57 \cdot 2 \%)$ & $-53 \cdot 7$ & $222 \cdot 3$ & & 0.79 (SE 0.06) \\
\hline Other/unknown & $206 / 482(42 \cdot 7 \%)$ & $219 / 460(47 \cdot 6 \%)$ & $-22 \cdot 8$ & $88 \cdot 0$ & & 0.77 (SE 0.09) \\
\hline \multicolumn{7}{|l|}{ (F) ER status $\left(\chi_{1}^{2}=0 \cdot 1 ; 2 p=0 \cdot 7 ; N S\right)$} \\
\hline ER-poor & $403 / 1095(36 \cdot 8 \%)$ & $464 / 1043(44 \cdot 5 \%)$ & $-40 \cdot 5$ & $180 \cdot 4$ & & 0.80 (SE 0.07) \\
\hline ER+ & $831 / 3100(26 \cdot 8 \%)$ & $1063 / 3177(33 \cdot 5 \%)$ & $-84 \cdot 6$ & 328.5 & & 0.77 (SE 0.05) \\
\hline ER unknown & $182 / 559(32 \cdot 6 \%)$ & $174 / 513(33 \cdot 9 \%)$ & $-14 \cdot 9$ & $72 \cdot 3$ & & 0.81 (SE 0.11) \\
\hline \multicolumn{7}{|l|}{ Subsets of ER+ } \\
\hline ER+, chemotherapy+endocrine vs endocrine & $659 / 2622(25 \cdot 1 \%)$ & $853 / 2675(31 \cdot 9 \%)$ & $-56 \cdot 2$ & $247 \cdot 0$ & & 0.80 (SE 0.06) \\
\hline ER 10-99 fmol/mg & 416/1371 (30:3\%) & $544 / 1442(37 \cdot 7 \%)$ & $-35 \cdot 3$ & $162 \cdot 5$ & & 0.80 (SE 0.07) \\
\hline$E R \geq 100 \mathrm{fmol} / \mathrm{mg}$ & $274 / 1146(23.9 \%)$ & $337 / 1160(29 \cdot 1 \%)$ & -20.6 & $95 \cdot 6$ & & 0.81 (SE 0.09) \\
\hline$E R+$, age $<55$ years & $250 / 845(29 \cdot 6 \%)$ & $316 / 943(33 \cdot 5 \%)$ & $-19 \cdot 4$ & $102 \cdot 4$ & & 0.83 (SE 0.09) \\
\hline$E R+$, age $55-69$ years & $542 / 2071(26 \cdot 2 \%)$ & $677 / 2055(32 \cdot 9 \%)$ & $-53 \cdot 9$ & $215 \cdot 3$ & & 0.78 (SE 0.06) \\
\hline ER+, poorly differentiated & $100 / 461(21 \cdot 7 \%)$ & $120 / 477(25 \cdot 2 \%)$ & $-12 \cdot 2$ & $45 \cdot 8$ & & 0.77 (SE 0.13) \\
\hline ER+, moderately/well differentiated & $228 / 985(23 \cdot 1 \%)$ & 286/1026 (27.9\%) & $-27 \cdot 8$ & $112 \cdot 8$ & & 0.78 (SE 0.08) \\
\hline \multirow{3}{*}{$\begin{array}{l}\text { Total } \\
\text { Global heterogeneity: } \chi_{6}^{2}=5 \cdot 8 ; p=0 \cdot 4\end{array}$} & $1416 / 4754(29 \cdot 8 \%)$ & $1701 / 4733(35 \cdot 9 \%)$ & $-139 \cdot 9$ & $581 \cdot 3$ & & $\begin{array}{l}0.786 \text { (SE } 0.037) \\
2 p<0.00001\end{array}$ \\
\hline & & & & $\begin{array}{c}0.5 \\
0.5 \\
\text { Anthracyclin }\end{array}$ & tter 1.0 & $\begin{array}{c}1 \cdot 5 \\
\text { Anthracycline worse }\end{array}$ \\
\hline & & & & \multicolumn{3}{|c|}{ Treatment effect $2 p<0.00001$} \\
\hline
\end{tabular}

Figure 6: Subgroup analyses of breast cancer mortality (mortality with recurrence, by log-rank subtraction) for any anthracycline-based regimen versus no chemotherapy

$\mathrm{A}=$ doxorubicin (Adriamycin). E=epirubicin. Dose/cycle (and cumulative dosage) is given after the drug name in $\mathrm{mg} / \mathrm{m}^{2} ; \mathrm{A} 60 / \mathrm{E} 90 \mathrm{means} 60 \mathrm{mg} / \mathrm{m}^{2}$ of doxorubicin or $90 \mathrm{mg} / \mathrm{m}^{2}$ of epirubicin. NS=not significant. ER=oestrogen receptor. *First four subgroups are as in the forest plots (webappendix pp 33-38) that give details of each trial's cytotoxic regimens. In the SWOG 8814 trial of CAF in postmenopausal ER+ disease, tamoxifen started randomly with or after the chemotherapy. 
versus CMF chemotherapy (figures 4 and 6) yields an RR of 0.77 (SE $0.07,2 p=0.002, n=3000)$, confirming at least some benefit of anthracycline-based regimens in this highER subgroup. Most women were aged 55-69 years at entry; results in the few who were older also suggest benefit (as in the taxane trials), but with wide uncertainty.

Figure 7 shows 10-year breast cancer mortality in trials of anthracycline-based regimens by age and ER status. The lack of apparent relevance of age or ER to the proportional risk reduction is somewhat confounded by regimen; almost half the evidence in older women with ER-positive disease (RR 0 78, SE 0 06, 2p=0 0002, n=4000) came from the one trial (SWOG8814'1) of CAF in 1500 postmenopausal women with tamoxifen-treated ER-positive disease, which showed that such chemotherapy substantially reduces breast cancer mortality in this major patient category.

In subgroup analyses for trials of standard or nearstandard CMF versus no chemotherapy (webappendix pp 13-14) the proportional risk reduction appeared inversely related to age and nodal status, but again appeared independent of ER status (RR for breast cancer mortality $0 \cdot 80$, SE $0 \cdot 10,2 p=0 \cdot 05$ for ER-poor disease and $0 \cdot 74$, SE $0 \cdot 07,2 p=0 \cdot 0002$ for ER-positive disease).

Among both older and younger women with ER-positive disease, the effects of chemotherapy added to those of effective endocrine therapy. Combining (webappendix $\mathrm{p} 6$, final section) these trials of CMF and the trials of anthracycline-based chemotherapy versus no chemotherapy, if both groups had 5 years of endocrine therapy then chemotherapy reduced breast cancer mortality both in women with entry age 55-69 years (chemoendocrine vs only endocrine therapy, RR $0 \cdot 78$, SE $0 \cdot 07,2 \mathrm{p}=0 \cdot 001$, $\mathrm{n}=3000$ ) and in younger women (RR 0.72 , SE 0.09 , $2 \mathrm{p}=0 \cdot 002, \mathrm{n}=2000)$. Of these younger women, half were known to be premenopausal or perimenopausal (with RR $0 \cdot 76$, SE $0 \cdot 13,2 \mathrm{p}=0 \cdot 06, \mathrm{n}=1000$ ), but information about chemotherapy-induced amenorrhoea was unavailable.

To help assess any life-threatening acute toxicity, the table on webappendix p 63 describes 1-year mortality without recurrence. In trials comparing two active regimens, this early mortality depended less on treatment group than on age, and before age 70 years it was relatively low (eg, 59/19477 [0.3\%] for taxane-plus-anthracyclinebased regimens vs 40/19386 [0.2\%] for anthracyclinebased control regimens, $2 \mathrm{p}=0 \cdot 06$ ). In trials of chemotherapy versus no chemotherapy, these 1-year hazards were notable only in the 1970s trials of 12 cycles of CMF and in one of the two trials ${ }^{11,15}$ of CAF.

There were also, as expected,${ }^{16-18}$ some deaths from acute myeloid leukaemia and anthracycline cardiotoxicity.

Figure 7: At least four cycles of any anthracycline-based regimen (with mean effect roughly as for standard $4 \mathrm{AC}$ ) versus no adjuvant chemotherapy: analyses of 10-year breast cancer mortality by age and ER status

RR (and its $95 \% \mathrm{Cl}$ )=event rate ratio, from summed log-rank statistics for all time periods combined. Gain (and its SE)=absolute difference between ends of graphs. ER=oestrogen receptor. Anth=anthracycline. Event rates, \%/year, are followed by (first events/woman-years). Error bars show \pm 1 SE

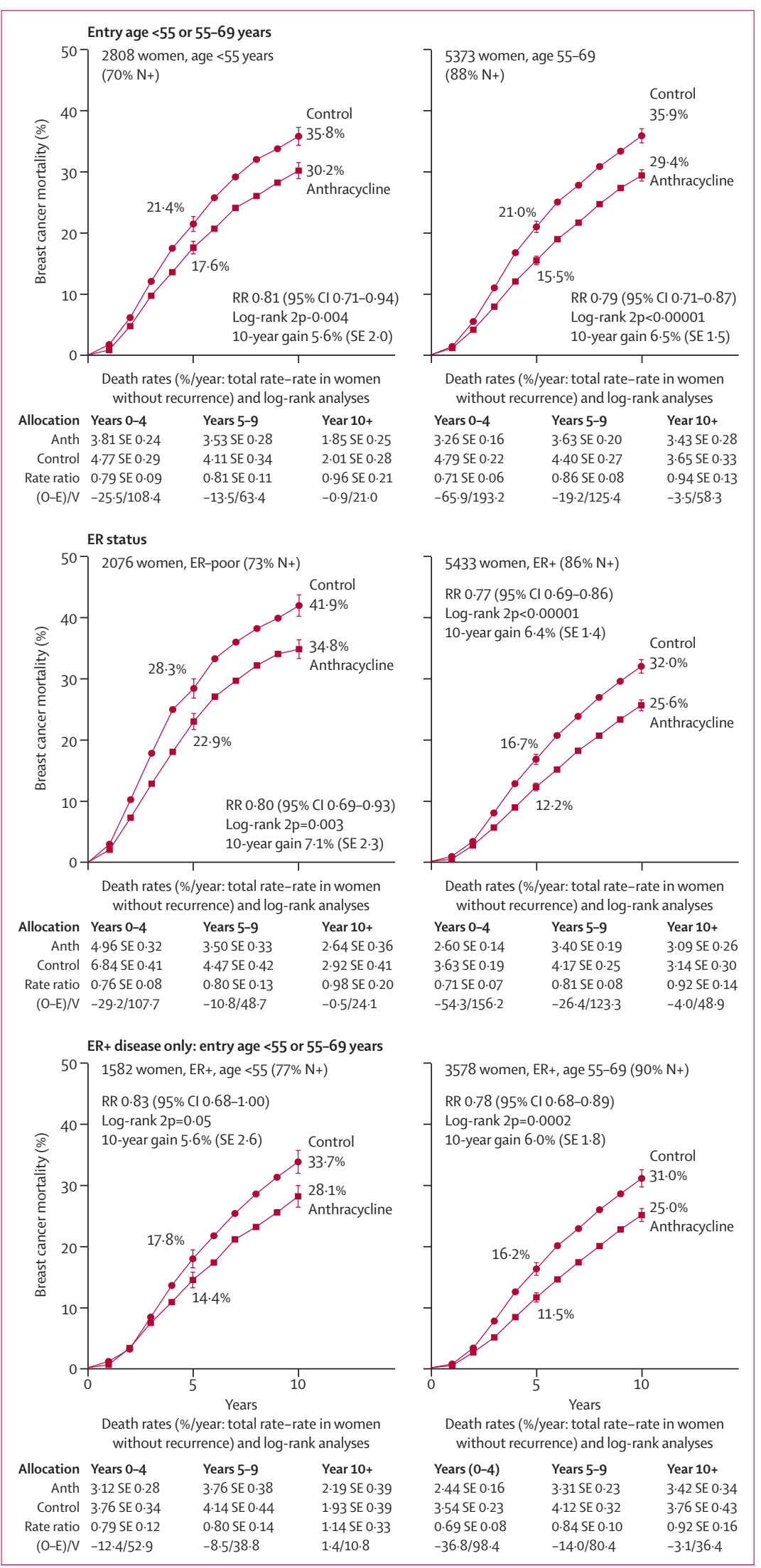


Numbers of acute myeloid leukaemia deaths without recurrence were 11 versus one for taxane plus other chemotherapy versus the same, or more, other chemotherapy; five each for anthracycline versus CMF; eight versus none for anthracycline versus nil; and one versus three for CMF versus nil. These excesses were mainly with two regimens: $225 \mathrm{mg} / \mathrm{m}^{2} /$ cycle paclitaxel $(7 / 1531[0 \cdot 5 \%]$ in the only trial) and CAF $(5 / 2638[0 \cdot 2 \%]$ in one trial and $2 / 1177[0 \cdot 2 \%]$ in the other). Undue emphasis on particular regimens can, however, exaggerate any real hazards, some trials did not report causes of death, and effective follow-up duration differs greatly in different trials. Cardiac mortality RRs for any anthracycline-based regimen were 1.50 (SE 0.38) versus CMF, 1.61 (SE 0.31) versus nil, and $1.56(\mathrm{SE} 0 \cdot 24,2 \mathrm{p}=0 \cdot 02)$ versus either. There were no other significant adverse effects on 10 -year non-breast cancer mortality, and overall mortality always matched breast cancer mortality (webappendix pp 18-20).

Powerpoints of all figures conclude the webappendix.

\section{Discussion}

These meta-analyses yield five main findings. First, standard CMF and standard 4AC were roughly equivalent: with either, 2-year recurrence rates were halved, recurrence rates during the next 8 years were reduced by one-third, and breast cancer mortality rates were reduced by $20-25 \%$. Second, regimens with significantly lower dose per cycle appeared, collectively, somewhat less effective. Third, regimens with substantially more chemotherapy than standard 4AC (but not so intensive as to require stem-cell rescue) were somewhat more effective: in comparisons versus standard $\mathrm{CMF}$ or $4 \mathrm{AC}$, a further proportional reduction of $15-20 \%$ in breast cancer mortality rates could be achieved by regimens such as $\mathrm{CAF}^{11,15}$ or $\mathrm{CEF}^{19}$ or by regimens such as 4AC plus four cycles of taxane (given 3-weekly; weekly paclitaxel may be promising, ${ }^{7,20}$ but was little studied). Reconciling reports of major benefit and no extra benefit in particular taxane trials, on average the taxane-plus-anthracycline-based regimens slightly but significantly improved outcome in comparison with an anthracycline-based control regimen (unless the taxane was counterbalanced in controls by roughly doubling the number of courses of other cytotoxic drugs). Fourth, in all chemotherapy comparisons 10 -year overall mortality was correspondingly reduced since there was little excess nonbreast-cancer mortality during the first year (partly because many patients got appropriate supportive care with, for some, substantial dose reductions to limit acute toxicity ${ }^{19}$ ) or after it.

Multiplying together breast cancer mortality RRs for the first and third of these findings (standard CMF or standard 4AC vs no chemotherapy, and more effective regimens $v s$ either of these; $0 \cdot 775 \times 0 \cdot 825=0 \cdot 64$ ) would suggest about $36 \%$ breast cancer mortality rate reduction for the more effective regimens versus no chemotherapy. Although proportional reductions are slightly smaller for 10 -year risks than for mortality rates (eg, a 36\% reduction in the death rate in each year would reduce a 10 -year risk of $30 \%$ to $20 \%$ ), this calculation still suggests that the 10 -year risk of death from breast cancer can be reduced by about a third, averaging over the different types of patient in these trials.

Finally, in all meta-analyses involving taxane-based regimens or anthracycline-based regimens, the proportional reductions in early recurrence, any recurrence, and breast cancer mortality appeared largely independent of age, nodal status, tumour diameter, tumour differentiation (poorly or moderately differentiated; relatively few were well differentiated), or ER status (ER-poor or ER-positive). Even in strongly ER-positive disease, chemotherapy did at least somewhat affect outcome, although not necessarily to exactly the same extent as in less strongly ERpositive disease. ${ }^{21,22}$

In premenopausal women chemotherapy generally causes permanent or transient amenorrhoea, and this suppression of ovarian function accounts for some of its efficacy in ER-positive disease. ${ }^{23,24}$ Chemotherapy must, however, have had additional effects on outcome in some women with ER-positive disease, since chemoendocrine therapy produced a substantially greater proportional reduction in breast cancer mortality than did endocrine therapy alone (or chemotherapy alone $e^{4}$ not only in women under 55 years of age but also in older women, in whom chemotherapy-induced amenorrhoea is irrelevant. ${ }^{11}$

Although age did not much affect the proportional risk reductions with taxane-based or anthracycline-based chemotherapy, the gain in life expectancy from a given absolute reduction in the risk of death from breast cancer is greater for younger than for older women, as more years are lost by death at 50 than at 70 years of age. Few women over 70 years of age entered these trials; they may have had somewhat greater immediate hazards from chemotherapy, but appear to have had as great a reduction as younger women in breast cancer recurrence and mortality.

A pathological complete response to neoadjuvant chemotherapy is more likely with ER-negative than with ER-positive tumours, and it has been suggested that ER status can in certain circumstances affect the proportional risk reduction with adjuvant chemotherapy. ${ }^{26-28}$ Yet, in these meta-analyses the proportional reductions in breast cancer recurrence and mortality with adjuvant chemotherapy were roughly independent of ER status (and, in ER-positive disease, of age and of the other available tumour characteristics). Although not centrally remeasured, the ER measurements were good enough for ER status to predict both tamoxifen responsiveness ${ }^{4}$ and risk during years $0-1$ (which was much greater in ER-poor than in ER-positive disease). Thus, there is no good reason to ascribe chemotherapy efficacy in ER-positive disease entirely to false-positive ER results (and, the proportional reductions in mortality rates were no greater in ERnegative than in ER-positive disease).

ER-positive disease is, however, heterogeneous, and can be broadly subdivided into luminal-A (HER2-negative, not 
highly proliferative, and generally well differentiated) and luminal-B (more highly proliferative and hence, perhaps, more chemosensitive). ${ }^{29}$ Poor differentiation, although not very reproducible between pathologists, is somewhat related to proliferation (and was measured well enough to predict poor prognosis), but in ER-positive disease it did not predict chemosensitivity.

We did not have data on luminal-A/B status or on modern markers of tumour cell biology that can help to predict high or low risk, such as quantitative immunohistochemical measurements of a standard set of four factors ${ }^{30}$ (two hormone receptors, HER2, and the proliferation-related protein Ki-67), or multigene expression signatures, based on tumour RNA profile. These signatures mainly reflect four groups of genes, which are also associated with ER status, progesterone receptor status, HER2 status, and proliferation. The joint relevance of such factors to prognosis stems mainly from the proliferation-related measurements. ${ }^{31-33}$

Certain trials ${ }^{22,34}$ have suggested that in ER-positive disease the levels of expression of various genes (including those related to proliferation) might correlate not only with prognosis but also with chemosensitivity, so they might help to predict benefit, or identify some higher-risk patients who would gain little from chemotherapy. We could not test such hypotheses. Three new trials (MINDACT, ${ }^{35}$ TAILORx, ${ }^{36}$ RxPONDER ${ }^{37}$ ) have included more than 10000 patients with ER-positive disease and measurements of gene expression profile who have been randomly allocated chemoendocrine therapy versus the same endocrine therapy alone. Their combined results will be able to assess reliably the prognostic relevance of such measurements (and of other measurements, including quantitative immunohistochemistry ${ }^{30}$ ) and will help to assess any differences in chemotherapy RRs between subgroups.

While awaiting the results of these new trials, it appears that ER status, differentiation, and the other tumour characteristics available for the present meta-analyses had little effect on the proportional risk reductions with taxane-based or anthracycline-based regimens. The more effective of these regimens offer on average a one-third reduction in 10-year breast cancer mortality, roughly independently of the available characteristics. The absolute gain from a one-third breast cancer mortality reduction depends, however, on the absolute risks without chemotherapy (which, for ER-positive disease, are the risks remaining with appropriate endocrine therapy). Although nodal status and tumour diameter and differentiation are of little relevance to the proportional risk reductions produced by such chemotherapy (and by tamoxifen therapy ${ }^{4}$ ), they can help in treatment decisions as they are strongly predictive of the absolute risk without chemotherapy, and hence of the absolute benefit that would be obtained by a one-third reduction in that risk.

Relatively few patients in these trials (and even fewer of those with recurrence) had small, well differentiated tumours. By contrast, widespread mammographic screening finds many breast cancers with low disease burden, low proliferative index, and hence a high probability of being endocrine-responsive luminal-A tumours. The present meta-analyses were not directly informative about the effects of chemotherapy on such low-risk tumours, but in low-risk ER-positive disease treated with effective endocrine therapy any further risk reduction from adding chemotherapy cannot, in absolute terms, be large, and patients not helped by chemotherapy are harmed by its toxicity. This includes not only acute toxicity and leukaemogenicity but also any persistent neurotoxicity and anthracycline cardiotoxicity. ${ }^{18}$ Longer follow-up of the trials will help to assess the eventual risks and benefits more reliably.

\section{Acknowledgments}

This report is dedicated to Paul Meier (1924-2011), parent of

Kaplan-Meier survival curves and effective advocate of widespread randomisation in US clinical research. ${ }^{38,39}$ The main acknowledgment is to the many participants in the trials and the many staff who treated them, undertook trials, and shared the data. EBCTCG is funded by core support to the Oxford University CTSU from Cancer Research UK, the British Heart Foundation, and the UK Medical Research Council; DC is supported by the BHF Centre for Research Excellence (RE/08/04).

Writing committee: a full list of 620 names of the EBCTCG collaborators has recently been published elsewhere ${ }^{4}$

Internal (CTSU) R Peto, C Davies, J Godwin, R Gray, H C Pan, M Clarke, D Cutter, S Darby, P McGale, C Taylor, Y C Wang; External J Bergh, A Di Leo, K Albain, S Swain, M Piccart, K Pritchard.

\section{Contributors}

Analyses were planned by RP, CD, JG, and RG (methodologists) in collaboration with JB and ADL (clinical advisors), and undertaken by JG, HCP, CD, RG, and RP in Oxford. RP, CD, RG, JB, and KP drafted the report and revised it with advice from KA, ADL, MP, SS, and HCP, then all writing committee members, then all collaborating trialists. Finally, it was agreed by the whole writing committee. The EBCTCG secretariat, including CD, JG, RG, MC, SD, PM, YCW, and RP, identified trials, obtained datasets, and had full access to them.

\section{Conflicts of interest}

MP holds patents on genome grade index and recurrence score (marketed by Ipsogen/Qiagen), KA has accepted infrequent honoraria for CME lectures and an ad hoc advisory board from Genomic Health Inc, and JB, ADL, KA, KP, and MP have each accepted honoraria or consultancy fees from 3-7 major pharmaceutical companies. SS and all internal writing committee members declare that they have no conflicts of interest. CTSU staff policy excludes honoraria or consultancy fees. EBCTCG is funded by Cancer Research UK, British Heart Foundation, and UK Medical Research Council grants. All writing committee members' institutions perform some trials sponsored by industry, government, or charity grants, which are undertaken and interpreted independently of the funders. Industrial support of trials contributing to EBCTCG meta-analyses is listed in the trial publications (webappendix pp 64-68); although such sponsorship might delay data from recent studies, it does not otherwise affect the analyses.

\section{Attendees at EBCTCG Steering Committee meetings}

K Albain, S Anderson, R Arriagada, W Barlow, J Bergh, J Bliss, *M Buyse, D Cameron, E Carrasco, * $\uparrow$ M Clarke, C Correa, A Coates, $* \uparrow R$ Collins, J Costantino, †D Cutter, J Cuzick, *†S Darby, N Davidson, * $\uparrow$ C Davies, $\uparrow$ K Davies, $\uparrow$ A Delmestri, A Di Leo, M Dowsett, $\uparrow$ P Elphinstone, $\uparrow$ V Evans, *M Ewertz, R Gelber, †L Gettins, C Geyer, A Goldhirsch, †J Godwin, $\uparrow R$ Gray, $\uparrow C$ Gregory, D Hayes, C Hill, J Ingle, R Jakesz, †S James, M Kaufmann, $†$ A Kerr, $\uparrow$ E MacKinnon, $\uparrow$ P McGale, $\uparrow$ T McHugh, L Norton, Y Ohashi, S Paik, $\uparrow$ H C Pan, E Perez, * $\uparrow$ R Peto, *M Piccart (co-chair), L Pierce, *K Pritchard (co-chair), G Pruneri, V Raina, P Ravdin, J Robertson, E Rutgers, Y F Shao, S Swain, †C Taylor, P Valagussa, G Viale, T Whelan, *E Winer, †Y Wang, *W Wood. *Executive Group, †Secretariat.
For more on the Clinical Trial Service Unit (CTSU) see http:// www.ctsu.ox.ac.uk/about/ 
References

1 Early Breast Cancer Trialists' Collaborative Group (EBCTCG) Effects of chemotherapy and hormonal therapy for early breast cancer on recurrence and 15-year survival: an overview of the randomised trials. Lancet 2005; 365: 1687-717.

2 Early Breast Cancer Trialists' Collaborative Group. Introduction and methods. In: Treatment of early breast cancer: worldwide evidence, 1985-1990. Oxford: Oxford University Press, 1990. http://www.ctsu.ox.ac.uk/reports/ebctcg-1990/index_html (accessed May 20, 2011).

3 Dowsett M, Cuzick J, Ingle J, et al. Meta-analysis of breast cancer outcomes in adjuvant trials of aromatase inhibitors vs tamoxifen. J Clin Oncol 2010; 28: 509-18.

4 Early Breast Cancer Trialists' Collaborative Group (EBCTCG). Relevance of breast cancer hormone receptors and other factors to the efficacy of adjuvant tamoxifen: patient-level meta-analysis of randomised trials. Lancet 2011; 378: 771-84.

5 Engelsman E, Klijn JCM, Rubens RD, et al. 'Classical' CMF vs a 3-weekly intravenous CMF schedule. Eur J Cancer 1991; 27: 966-70.

6 Peto R. Current misconception 3: that subgroup-specific trial mortality results often provide a good basis for individualising patient care. Br J Cancer 2011; 104: 1057-58.

7 Martín M, Rodríguez-Lescure A, Ruiz A, et al for the GEICAM 9906 investigators. Randomized phase 3 trial of fluorouracil, epirubicin, and cyclophosphamide alone or followed by paclitaxel for early breast cancer. J Natl Cancer Inst 2008; 100: 805-14.

8 Wolff AC, Hammond MEH, Schwartz JN, et al. American Society of Clinical Oncology/College of American Pathologists guideline recommendations for human epidermal growth factor receptor 2 testing in breast cancer. Arch Pathol Lab Med 2007; 131: 18-43.

9 Bonneterre JM, French Adjuvant Study Group. Long-term efficacy and toxicity of the FEC100 regimen. Oncology (Willston Park) 2004; 18 (suppl 14): 56-58.

10 Henderson IC, Berry DA, Demetri GD, et al. Improved outcomes from adding sequential paclitaxel but not from escalating doxorubicin dose in an adjuvant chemotherapy regimen for patients with node-positive primary breast cancer. J Clin Oncol 2003; 21: 976-83.

11 Albain KS, Barlow WE, Ravdin PM, et al, for the Breast Cancer Intergroup of North America. Adjuvant chemotherapy and timing of tamoxifen in postmenopausal patients with endocrine-responsive, node-positive breast cancer: a phase 3, open-label, randomised controlled trial. Lancet 2009; 374: 2055-63.

12 Pico C, Martin M, Jara C, et al, on behalf of the GEICAM Group. Epirubicin-cyclophosphamide adjuvant chemotherapy plus tamoxifen administered concurrently versus sequentially: randomized phase III trial in post-menopausal node-positive breast cancer patients. A GEICAM 9401 study. Ann Oncol 2004; 15: 79-87.

13 Bedgonetti D, Sertoli MR, Pronzato P, et al. Concurrent vs sequential adjuvant chemotherapy and hormonal therapy in breas cancer: a multicenter randomized phase III trial. J Natl Cancer Inst 2011; 103: 1529-39.

14 International Breast Cancer Study Group (IBCSG). Toremifine and tamoxifen are equally effective for early-stage breast cancer first results of IBCSG trials 12-93 and 14-93. Ann Oncol 2004; 15: 1749-59.

15 Hutchins LF, Green SJ, Ravdin PM, et al. Randomized, controlled trial of cyclophosphamide, methotrexate, and fluorouracil versus cyclophosphamide, doxorubicin, and fluorouracil with and without tamoxifen for high-risk, nodenegative breast cancer: treatment results of Intergroup protocol INT-0102. J Clin Oncol 2005; 23: 8313-21

16 Praga C, Bergh J, Bliss J, et al. Risk of acute myeloid leukemia and myelodysplastic syndrome in trials of adjuvant epirubicin for early breast cancer: correlation with doses of epirubicin and cyclophosphamide. J Clin Oncol 2005; 23: 4179-91.

17 van Dalen EC, van der Paul HJH, Caron HN, Kremer LCM Different dosage schedules for reducing cardiotoxicity in cancer patients receiving anthracycline chemotherapy (review). Cochrane Database Syst Rev 2009; 4: CD005008.

18 Azim HA, de Azambuja E, Colozza M, Bines J, Piccart MJ. Long-term toxic effects of adjuvant chemotherapy in breast cancer. Ann Oncol 2011; 22: 1939-47.
19 Levine MN, Bramwell VH, Pritchard KI, et al. Randomized trial of intensive cyclophosphamide, epirubicin, and fluorouracil chemotherapy compared with cyclophosphamide, methotrexate, and fluorouracil in premenopausal women with node-positive breast cancer. J Clin Oncol 1998; 16: 2651-58.

20 Sparano JA, Wang M, Martino S, et al. Weekly paclitaxel in the adjuvant treatment of breast cancer. $N$ Engl J Med 2008; 358: 1663-71.

21 Pagani O, Gelber S, Simoncini E, et al. Is adjuvant chemotherapy of benefit for postmenopausal women who receive endocrine treatment for highly endocrine-responsive, node-positive breas cancer? International Breast Cancer Study Group trials VII and 12-93. Breast Cancer Res Treat 2009; 116: 491-500.

22 Albain KS, Barlow WE, Shak S, et al, for the Breast Cancer Intergroup of North America. Prognostic and predictive value of the 21-gene recurrence score assay in postmenopausal women with node-positive oestrogen-receptor-positive breast cancer on chemotherapy: a retrospective analysis of a randomised trial. Lancet Oncol 2010; 11: 55-65.

23 Brinker H, Rose C, Rank F, et al. Evidence of a castration-mediated effect of adjuvant cytotoxic chemotherapy in premenopausal breast cancer. J Clin Oncol 1987; 5: 1771-78.

24 Walshe JM, Denduluri N, Swain SM. Amenorrhea in premenopausal women after adjuvant chemotherapy for breast cancer. J Clin Oncol 2006; 24: 5769-79.

25 Straver ME, Glas AM, Hannemann J, et al. The 70-gene signature as a response predictor for neoadjuvant chemotherapy in breast cancer. Breast Cancer Res Treat 2010; 119: 551-58.

26 Montagna E, Bagnardi V, Rotmensz N, et al. Pathological complete response after preoperative systemic therapy and outcome: relevance of clinical and biologic baseline features. Breast Cancer Res Treat 2010; 124: 689-99.

27 International Breast Cancer Study Group (IBCSG). Endocrin responsiveness and tailoring adjuvant therapy for postmenopausal lymph node-negative breast cancer: a randomized trial. J Natl Cancer Inst 2002; 94: 1054-65.

28 Berry DA, Cirrincione C, Henderson IC, et al. Estrogen-receptor status and outcomes of modern chemotherapy for patients with node-positive breast cancer. JAMA 2006; 295: 1658-67.

29 Wirapati P, Sotiriou C, Kunkel S, et al. Meta-analysis of gene expression profiles in breast cancer: toward a unified understanding of breast cancer subtyping and prognosis signatures. Breast Cancer Research 2008; 10: R65.

30 Cuzick J, Dowsett M, Pineda S, et al. Prognostic value of a combined estrogen receptor, progesterone receptor, Ki-67, and human epidermal growth factor receptor 2 immunohistochemical score and comparison with the genomic health recurrence score in early breast cancer. J Clin Oncol 2011; published online Oct 11. DOI:10.1200/JCO.2010.31.2835.

31 Sotiriou C, Pusztai L. Gene-expression signatures in breast cancer. N Engl J Med 2009; 360: 790-800.

32 Paik S, Shak S, Tang G, et al. A multigene assay to predict recurrence of tamoxifen-treated, node-negative breast cancer. N Engl J Med 2004; 351: 2817-26.

33 Dowsett M, Cuzick J, Wale C, et al. Prediction of risk of distant recurrence using the 21-gene recurrence score in node-negative and node-positive postmenopausal patients with breast cancer treated with anastrazole or tamoxifen: a TransATAC study. J Clin Oncol 2010; 28: 1829-34.

34 Paik S, Tang G, Shak S, et al. Gene expression and benefit of chemotherapy in women with node-negative, estrogen-receptorpositive breast cancer. J Clin Oncol 2006; 24: 3726-34.

35 Cardoso F, Piccart-Gebhart M, van't Veer L, Rutgers E. The MINDACT trial: the first prospective clinical validation of a genomic tool. Mol Oncol 2007; 1: 246-51.

36 Sparano JA. TAILORx: trial assigning individualised options for treatment (Rx). Clin Breast Cancer 2006; 7: 347-50.

37 Gonzalez-Angulo AM, Barlow WE, Gralow J, et al. SWOG S1007: a phase III, randomized clinical trial of standard adjuvant endocrine therapy $+/-$ chemotherapy in patients with $1-3$ positive nodes, hormone receptor (HR)-positive and HER2-negative breast cancer with recurrence score (RS) of 25 or less (RxPONDER, NCT01272037). Proc Am Soc Clin Oncol 2011; 29 (suppl): abstr TPS104.

38 Kaplan EL, Meier P. Nonparametric estimation from incomplete observations. J Am Stat Assn 1958; 53: 457-81.

39 Marks HM. A conversation with Paul Meier. Clin Trials 2004; 1: 131-38. 